\title{
WAYS TO INCREASE ENERGY EFFICIENCY IN THE POWER SYSTEM USING THE EXAMPLE OF THE REPUBLIC OF TAJIKISTAN
}

\author{
MUNIRA HALIMJANOVA, KLAUS-DIETER DETTMANN, DETLEF SCHULZ, \\ GESA KAATZ, FLORIAN GRUMM \& MARC FLORIAN MEYER \\ Electrical Power Systems, Helmut Schmidt University / University of the Federal Armed Forces, Germany
}

\begin{abstract}
The Republic of Tajikistan has big problems with its electrical power system. It has high losses, low overall efficiency and a low reliability. Total blackouts even occur, although the country has a great potential for hydropower. More than $87 \%$ of the power system comprises hydropower plants, but many of them are very old and work inefficiently. Furthermore, the water in the rivers of Tajikistan comes mainly from mountains and thus the quantity is seasonally dependent. In wintertime, these power plants suffer from water shortage, and in summertime, the power system suffers from overloaded transmission lines. Nevertheless, the power plants could produce more electrical power in summertime if there were more demand and more transmission capabilities. There would even exist the generation capacity for exporting power to neighbouring countries. This article reveals such deficits in the Tajik power system and describes possible solutions. First of all, the Republic of Tajikistan should focus on the modernization of existing power plants and voltage lines. The main challenges are to increase the energy production, transmission, distribution and use. Furthermore, the power grid needs a higher reliability. Single faults in the system should not result in blackouts. These important aspects of the energy system have gained special awareness in recent years. For the planning of much-needed new power plants and new or enhanced transmission lines, it is essential to optimize the locations where these enhancements are realized. For this purpose, simulations are necessary.

Keywords: combined heat and power plant (CHP), hydropower plant (HPP), energy security, transmission lines, reactive power compensation, DIgSILENT PowerFactory 2017, Republic of Tajikistan, efficiency, reliability, power quality.
\end{abstract}

\section{INTRODUCTION}

The Republic of Tajikistan is situated in Central Asia with Uzbekistan in the west, Uzbekistan and Kyrgyzstan in the north, Afghanistan in the south and China in the east. The area of Tajikistan amounts to 143.1 thousand $\mathrm{km}^{2}$ with a population of about 8.7 million. The main natural energy resources are hydro and solar energy [1]. Tajikistan is a leader in hydro-energetic resources in the central Asian region. Around 8\% of the territory is covered with glaciers. Glaciers are important for Tajikistan, because they are sources of water and regulate the river flow. There are over 9000 glaciers in the country, with a total area of $8,470 \mathrm{~km}^{2}$. Tajikistan has more than 25,000 rivers with a total length of about $90,000 \mathrm{~km}$. Despite this great potential, Tajikistan remains a country with low power supply security, low power reliability and low power quality.

\section{PROBLEM DESCRIPTION}

Tajikistan has big problems with its electricity supply, especially in the wintertime. These difficulties arise from the fact that more than $87 \%$ of the country's power production comprises hydropower plants (HPPs) [2]. The general potential of Tajikistan's hydroenergetic resources is around $527 \mathrm{TWh}$ per year. However, today only about $3 \%$ of this potential is used. 
Actually, the total installed power amounts to $5681 \mathrm{MW}$, which is composed of:

1. $4963 \mathrm{MW}$ of HPPs (87.4\%); and

2. $718 \mathrm{MW}$ combined heat and power plants (CHPs) (12.6\%).

Fig. 1 shows a map of the Republic with all current and future HPPs. The blue squares show HPPs in operation, the green triangles are HPPs under construction and the red dots are future HPPs. Today, 13 HPPs are in use. The biggest HPP of Central Asia (Rogun) is under construction. It will have a nominal power of $3600 \mathrm{MW}$. After the completion of Rogun the total capacity of the Tajik energy system will amount to $9281 \mathrm{MW}$. Moreover, the 37 future HPPs shown in Fig. 1 have a total capacity of about $20.6 \mathrm{GW}$.

As presented in Fig. 2, in summertime, most HPPs produce electrical power with a very low efficiency [3]. Similar values are shown in Fig. 3, which illustrates the efficiencies of the HPPs in wintertime. The water in the rivers of Tajikistan comes mainly from mountains - as, for example, melting snow or ice - and thus is seasonally dependent. Further, it should be noted that most of the HPPs under operation are more than 45 years old and need to be renovated as fast as possible.

HPP Norak is one of the biggest hydropower power plants in Central Asia. Like several other HPPs, it is located on the River Vachsh. It has nine generators with an overall capacity of $3000 \mathrm{MW}$. The first two generators in HPP Norak were put into operation in 1972 and since 1979 operate at nominal power. Unfortunately, over the years the storage reservoir of HPP Norak became contaminated with sediments, because it is located closest to the river's spring. From 1972 to 2001 the storage reservoir lost about 1.96 billion $\mathrm{m}^{3}$ of its useable volume. Consequently, the efficiency decreased and today is at about $67 \%$. Usually when HPPs are constructed, they have efficiencies above $90 \%$. The sedimentation process at HPP Norak will stop when the HPP Rogun is completed, because it is located higher up the river than HPP Norak.

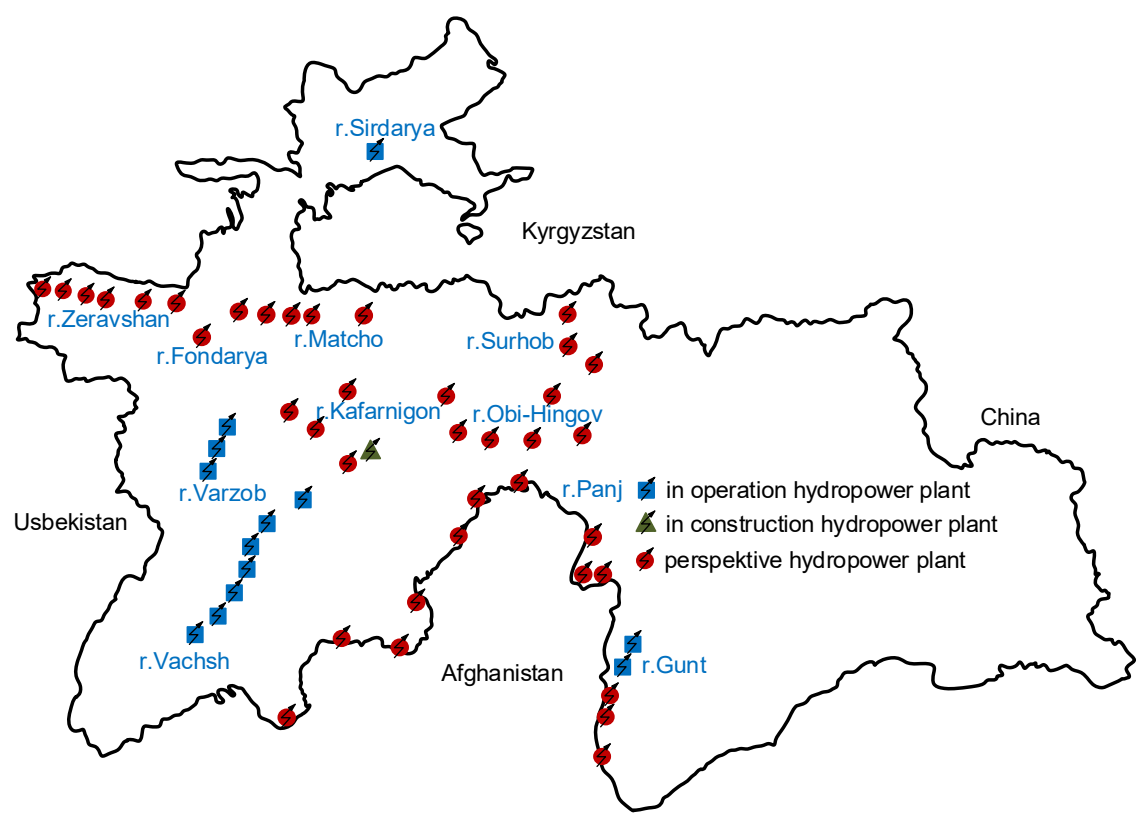

Figure 1: Status and perspective of HPPs in Tajikistan (r.Vachsh: River Vachsh). 


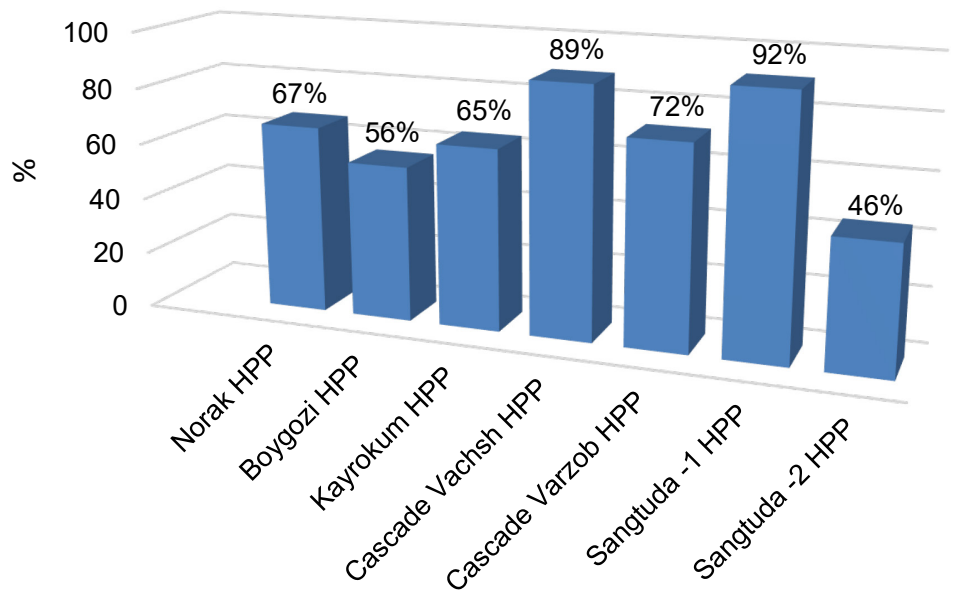

Figure 2: Efficiency of the Tajik HPPs in summertime.

HPP Sangtuda-1, also located on the River Vachsh, was put into operation in 2009. This new HPP was constructed considering the very latest standards and is today running at the highest efficiency $(91.5 \%)$. This shows how important renovations and modernizations are for the Tajik energy system.

As shown in Fig. 3, in wintertime the efficiency of nearly all the HPPs decreases, due to lower water levels (data from personal communication with the Ministry of Energy and Industry of the Republic of Tajikisatan, 2016). The two CHPs - CHP-2 and CHP Dushanbe - operate only in wintertime, because in summertime all the HPPs produce enough electrical energy for covering the country's power demand, and producing electrical energy in a thermoelectric plant is more expensive than in a HPP. It should be noted that CHP Dushanbe was built in 1961 and has not been modernized since its construction [2].

The Tajik Energy Company "Barki Tojik" will try to export the summer surplus energy (4.75 TWh in 2015 [3]) to neighbouring countries. This project is very important, because the possibility of exporting energy allows the Tajik HPPs to operate with higher efficiencies. The income from the exported energy can help renovating the energy system [3]. As a result, the reliability and security of the Tajik energy system will increase.

In the Tajik power grid, there are four $500 \mathrm{kV}$ substations and twenty-one $220 \mathrm{kV}$ substations (see Fig. 4). The red lines and dots mark the $500 \mathrm{kV}$ grid. The green lines and dots show the $220 \mathrm{kV}$ transmission lines and substations. Also presented in the figure are future $500 \mathrm{kV}$ and $220 \mathrm{kV}$ lines and substations, as well as future connections to neighbouring countries.

In today's Tajik energy system only two high-voltage power substations are equipped with reactive power compensation. These are the substations Sugd and Dushanbe. Reactive power sources are installed on the low-voltage side of these substations and do not help increasing the voltage to its nominal value, due to the very high power demand in wintertime and power losses in the high-voltage transmission lines. 


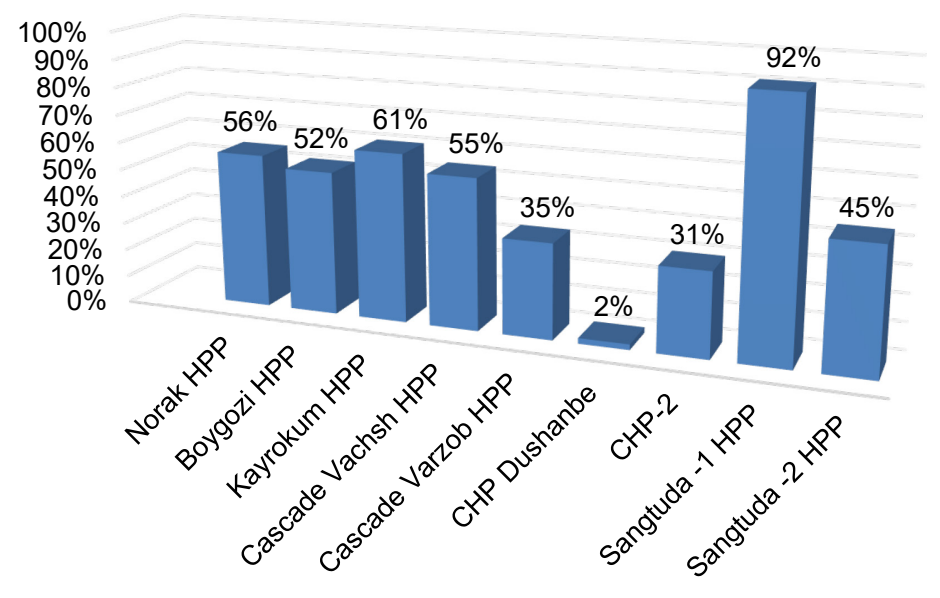

Figure 3: Power plant efficiency in wintertime in Tajikistan (the CHPs CHP-2 and CHP Dushanbe operate only in wintertime).

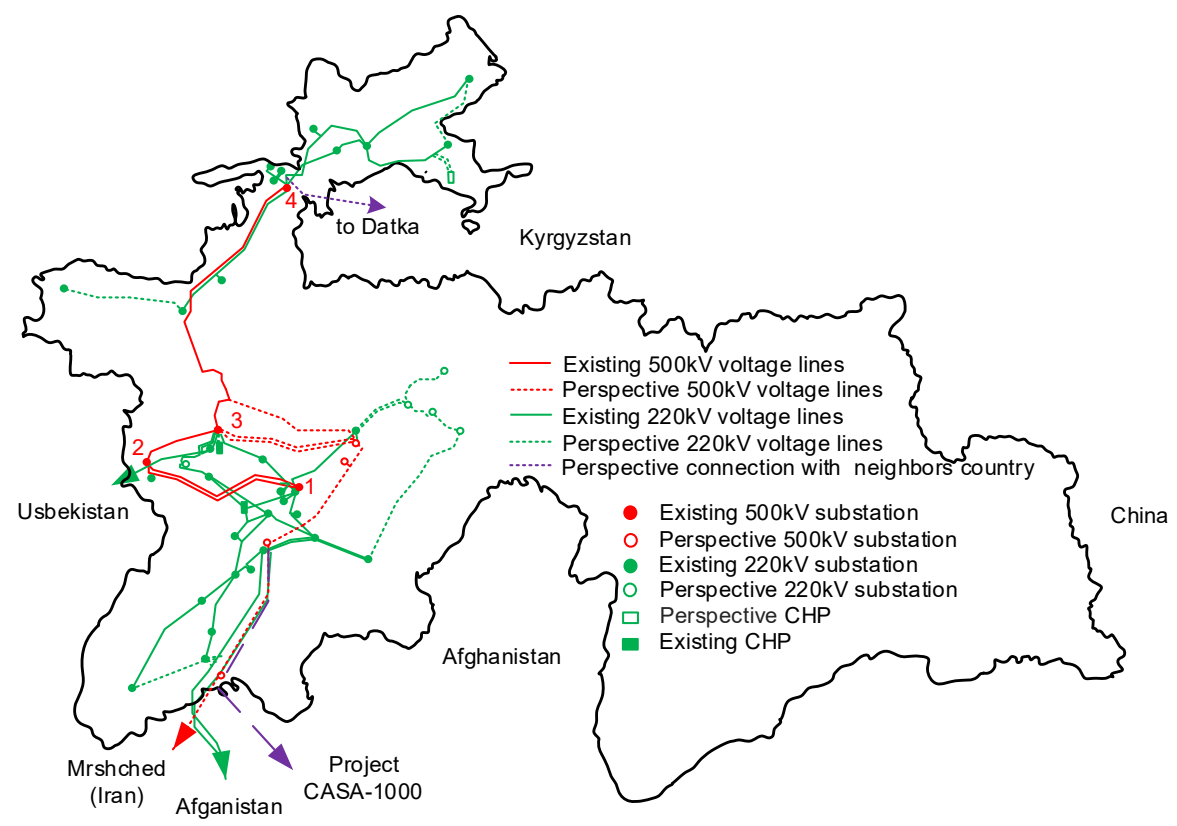

Figure 4: Existing and perspective $500 \mathrm{kV}$ and $220 \mathrm{kV}$ substations and voltage lines in the Tajik energy system. 
An initial calculation using DIgSILENT's software PowerFactory showed several problems in the Tajik energy system:

1. Low efficiency of power plants (HPP: $46-92 \%$ in summertime and $35-92 \%$ in wintertime of achievable 94\%, CHP: $2-31 \%$ electrically of achievable $38 \%$ ).

2. Power deficit in the wintertime 4.3 TWh [1].

3. Overloaded transmission lines like the $220 \mathrm{kV}$ voltage line L-D-N1. It connects the substation Dushanbe $(500 / 220 \mathrm{kV})$ to the substation Novaya $(220 / 110 / 10 \mathrm{kV})$, which is operated at $145 \%$ of its rated load (see Table 1).

4. Overloaded transformers and too low voltages at the substations' busbars. For example, the substation Sugd has three different voltage levels, $500 \mathrm{kV}, 220 \mathrm{kV}$, $35 \mathrm{kV}$ and two transformers with a total capacity of $500 \mathrm{MVA}$. Both of them are operated at $131 \%$ of their rated loads (see Fig. 5). In this situation, the subsequent problems follow:

a. The output voltage drops, degrading voltage stability and making it much more difficult to black start devices [4].

b. The generation of electrical heat losses is proportional to the square of the current. Thus, if the transformer is overloaded by $31 \%$, the losses increases by approximately $72 \%[4]$.

5. Underutilized transformers (see Fig. 6). Result: magnetization losses when idling [5].

6. Absence or insufficient use of voltage control and reactive power compensation. Result: voltage instability and reduced quality of electrical power.

Table 1. Overloaded high-voltage lines in the Tajik energy system.

\begin{tabular}{|l|c|c|c|}
\hline Name of line & Voltage $[\mathrm{kV}]$ & Length $[\mathrm{km}]$ & Load [\%] \\
\hline L-D-D & 220 & 73.2 & 315 \\
\hline L-D-N1 & 220 & 16.6 & 145 \\
\hline L-D-N2 & 220 & 10.9 & 221 \\
\hline L-D-O & 220 & 26.1 & 227 \\
\hline L-N-P & 220 & 47.5 & 233.9 \\
\hline L-702a & 220 & 44.7 & 287 \\
\hline L-702 & 220 & 2.5 & 152 \\
\hline L-7O-2 & 220 & 2.5 & 135 \\
\hline L-7-10(1) & 220 & 0.5 & 145.8 \\
\hline L-7-10a & 220 & 47.2 & 206 \\
\hline L-7L(1) & 220 & 25 & 250 \\
\hline L-7L & 220 & 18.1 & 274 \\
\hline L-810 & 220 & 1.6 & 382 \\
\hline L-810(1) & 220 & 1.6 & 313 \\
\hline L-10D & 220 & 31.9 & 193 \\
\hline L-8D & 220 & 53.4 & 179 \\
\hline L-85(1) & 220 & 1.4 & 335 \\
\hline L-85 & 220 & 1.4 & 304 \\
\hline L-12-5 & 220 & 13.5 & 215 \\
\hline L-11-12 & 220 & 14 & 126 \\
\hline L-12-5 & 220 & 13.5 & 150 \\
\hline L-11L-1 & 220 & 33 & 115 \\
\hline L-11L-2 & 220 & 33 & 115 \\
\hline
\end{tabular}


Fig. 5 shows several problems in the substation Sugd regarding the power quality design. Today, the substation Sugd supplies nine other substations of the $220 \mathrm{kV}$ grid. In wintertime, its load usually increases to about $500 \mathrm{MW}$. At full load, the load flow simulation in PowerFactory did not converge, which means that the system cannot cover the load. Furthermore, in overload conditions the voltage drops and power losses increase. For example, with a load of only $301 \mathrm{MW}$ both transformers are operated at $131 \%$ of their rated load and the voltage drops from $500 \mathrm{kV}$ to $381 \mathrm{kV}$ (see Fig. 5). Further simulations show that today the substation Sugd can cover only about $60 \%$ of the required peak load of $500 \mathrm{MW}$.

Even at a load of merely $45 \%$ of the $500 \mathrm{MW}$, the problem of the high-voltage drop remains (see Fig. 6). This happens because the energy system cannot cover the power demand. As a result, the power quality in this region is very low [6].

Because of all the problems addressed above, the Tajik energy system is confronted with many difficulties, such as low reliability and high losses. For example, in the last decade, the Tajik energy system suffered two total blackouts. The first one occurred in wintertime and the second one in autumn. The whole country was plunged into darkness for a full day. Similar situations can occur if no measures are taken soon.

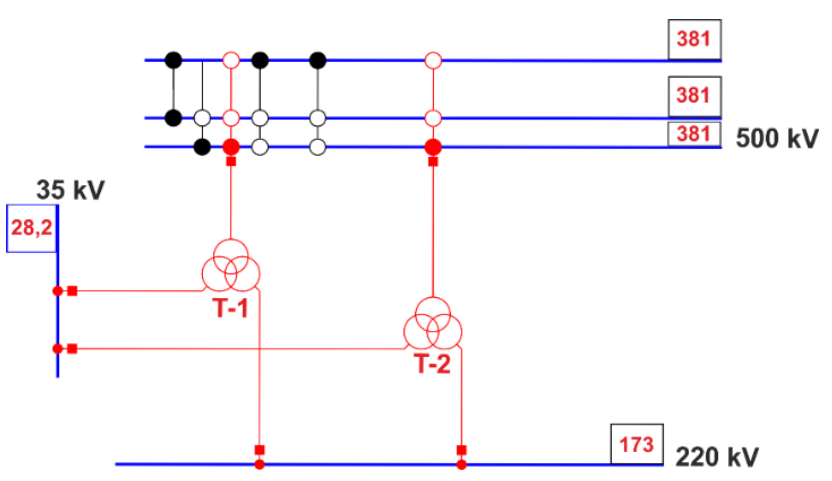

Figure 5: Substation Sugd (500/220/35 kV) at overload condition.

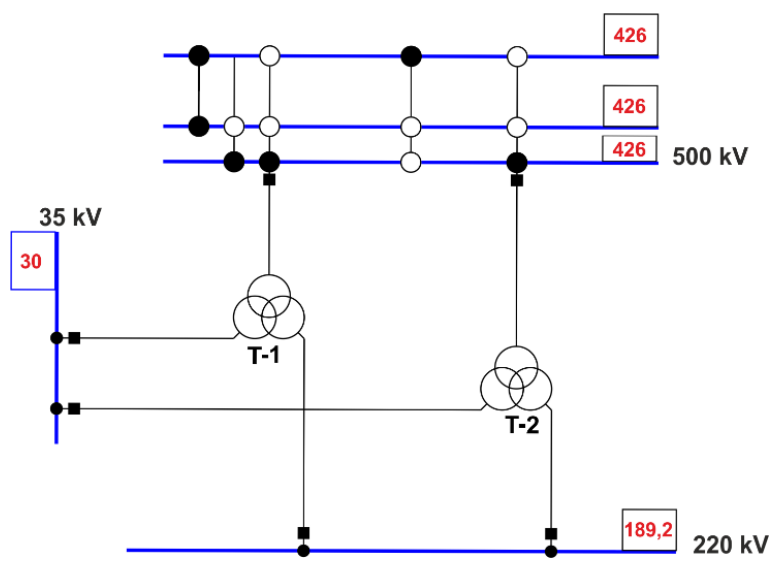

Figure 6: Substation Sugd (500/220/35 kV) at low loads. 


\section{PROPOSED SOLUTION}

Improving the energy supply in the northern part of the country becomes more important, because the low quality of the power system on one side of the country decreases the electric power quality in the whole Tajik energy system. Of course, in order to increase the reliability and power quality it is necessary to connect new power generation capacities to the grid. However, as the simulations show, it is also important to find the optimal locations for these additional power plants.

For example, new developing projects are planned in Tajikistan. In these programs two new CHP shall be constructed, one with a capacity of 300 MVA to be connected to the substation Konibodom and a second one with a capacity of 100 MVA, which will feed in the substation Hujand. These substations are located in the northern part of the country and will be connected to the substation Sugd via $220 \mathrm{kV}$ lines. Unfortunately, the simulation shows that connecting these new power plants is not sufficient to increase the voltages in the northern part of the country (see Fig. 7).

As presented in Fig. 7, the HPP Kayrokum is situated between the two new CHPs. Before these two CHPs are connected, the transformers of HPP Kayrokum operate at $288 \%$ of their rated load. Afterwards, their load will decrease to $233 \%$, so they still operate in a critical condition.

Further capacity from the new CHP is helpful, but not enough in order to increase the power quality and power reliability in the northern part of the Tajik energy system. The connection of these two CHPs to the substations Konibodom and Hujand shows positive and negative effects:

1. The voltages at the substations increase, but still stay under the nominal operating voltage.

2. The transformers in the substation Sugd are not overloaded.

3. The load of the transformers at the HPP Kayrokum decreases from $288 \%$ to $233 \%$.

4. The total produced power is not enough for covering the load.

5. The investment is not effective.

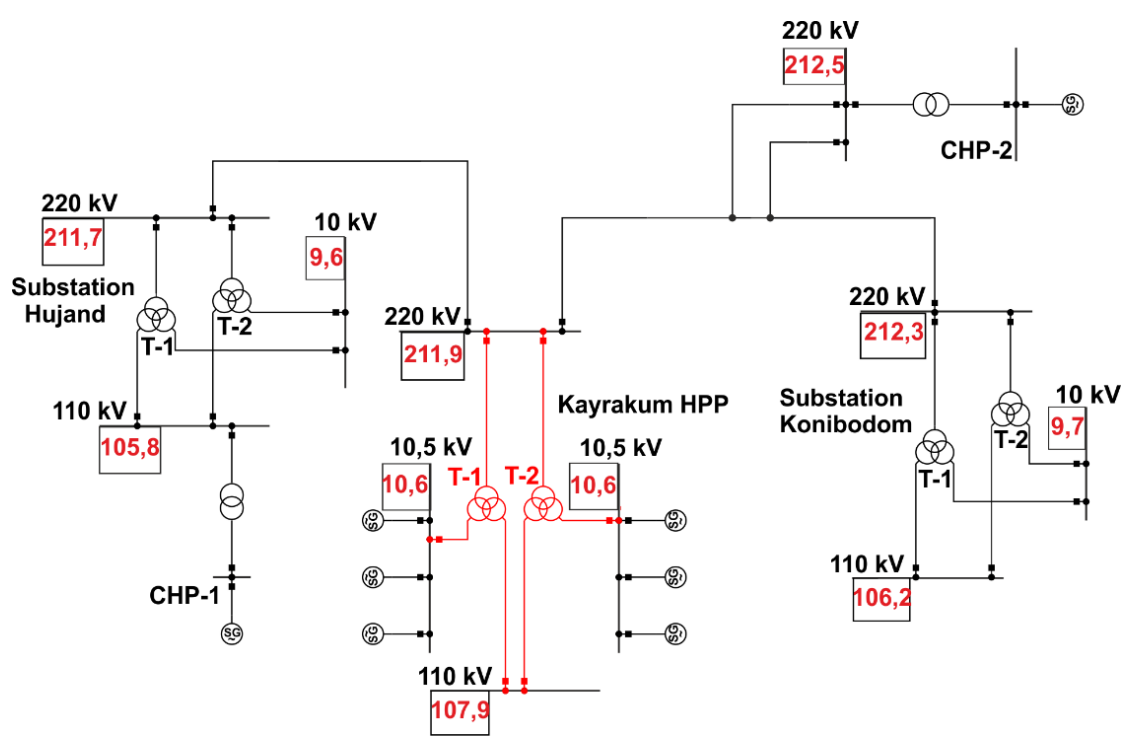

Figure 7: Connecting two CHPs to the energy system. 
Nevertheless, the northern part of the country needs more capacities. A possible solution is constructing one CHP with two $220 \mathrm{MW}$ turbogenerators instead of CHP-1 and CHP-2, connecting it between the substation Konibodom and the HPP Kayrokum (see Fig. 8).

After connecting this single new CHP, the voltages at all substations increase. Moreover, the produced power matches the load of $500 \mathrm{MW}$, which means that in the northern part of the country the total load is covered. The transformers in the substation Sugd can now work at their nominal operating conditions and the substation can even supply a higher load. The load of the transformers of HPP Kayrokum decreases to $177 \%$ of their rated load. It should be noted that after connecting new capacities, some part of the energy system needs to be modernized. For example, the power line between the new CHP and the HPP Kayrokum should be replaced by a power line with a higher cross-section of $400 \mathrm{~mm}^{2}$, because it is loaded by $123 \%$ of its rated load (see the red coloured line in Fig 8).

While improving the northern part of the Tajik energy system, the new capacities also help increasing power reliability and quality in the whole system. Nevertheless, blackouts can still occur in case of critical failures. To avoid such disasters, the grid should be able to continue operating if one arbitrary device fails. This means that the grid needs additional transmission lines, transformers and other devices. In Europe, this safety level is called n-1 fail-safe operation, which is common in all power grids. Beyond this level of fail-safe operation, the grid needs even more redundancy, if the fail-safe operation shall also be guaranteed while maintenance operations occur. In this case, the grid must be fault-tolerant to two simultaneous failures, which is the case in essential European transmission grids.

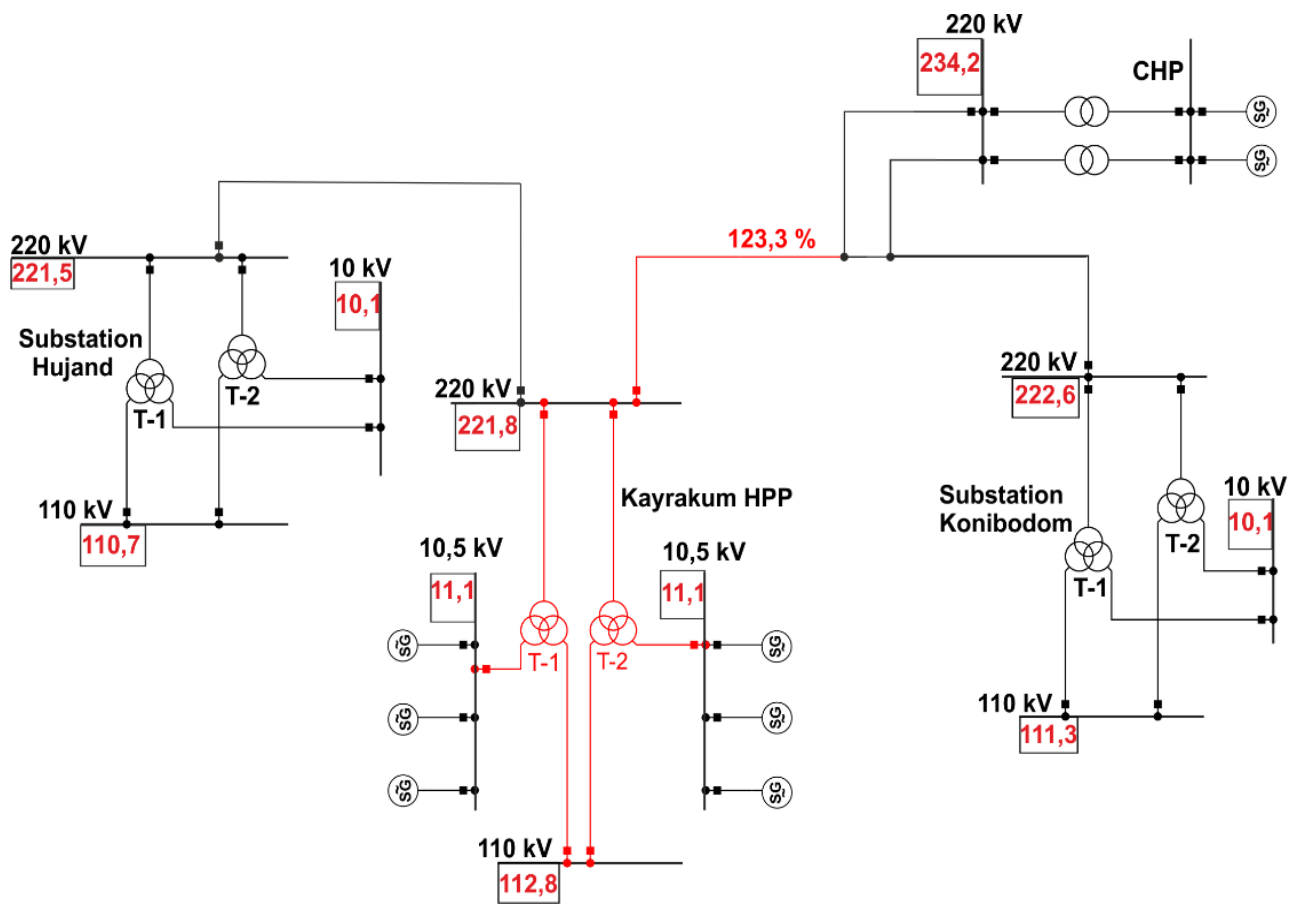

Figure 8: Connecting one CHP to the energy system. 


\section{CONCLUSION}

It is necessary to maximize the usage of the produced energy, to minimize the technical losses and to increase the reliability, especially voltage stability, in the Tajik energy system. Simulations of the Tajik grid have identified overloaded lines and substations in the $220 \mathrm{kV}$ grid. This must be avoided for reasons of safety and reliability. Thus, new CHPs are planned at present. For two of these CHPs, it is shown that they will be ineffective when connected to the designated substations in the northern part of the country. A better technical and economical solution is proposed. To avoid future blackouts, the grid should be constructed as fail-safe for one single fault and in essential ranges even for two simultaneous faults. All calculations are based on real data and are performed with the simulation software DIgSILENT PowerFactory 2017, which helped to reveal existing problems in the Tajik energy system.

\section{REFERENCES}

[1] Schulz, D., Akhrorova, A.D., Halimjanova, M.K. \& Kholov, Kh., Energy supply of mountain settlements in Tajikistan is based on renewable energy sources. Energy Production and Management in the 21st Century / The Quest for Sustainable Energy, Vol. 2, pp. 971-978, 2014.

[2] Halimjanova, M., Schulz, D., Dettmann, K.-D. \& Akhrorova, A., Energy efficiency in the context of energy availability in the Republic of Tajikistan. WIT Transactions on Ecology and the Environment, 205, pp 115-123, 2016.

[3] Akhrorova, A., Boboev, F., Halimjanova, M., Dettmann, K.-D. \& Schulz, D., Diversification of energy sources in the Republic of Tajikistan and their financing. Conference on Sustainable Energy Supply and Energy Storage Systems (NEIS 2016), Hamburg, Germany, 15-16 Sep. 2016.

[4] Controlled Power Company, Overloads - application notes from 22 April 1988, http://www.controlledpwr.com/whitepapers/ukloada1.pdf. Accessed on: 2 Jun. 2016.

[5] Lantsov, A., Quality parameters of electricity, http://e-audit.ru/quality/no_sinus.shtml. (accessed on: 2 Jun. 2016).

[6] Dugan, R.C., McGranaghan, M.F., Santoso, S. \& Baety, H.W., Electrical Power Systems Quality, 2nd ed., Publishing Copyrighted Material, pp. 20-25, 2004. 